\title{
FAKTOR RISIKO KELELAHAAN KERJA PADA OPERATOR SPBE PT PUTRA ARBA MANDIRI PALU
}

\author{
Risk Factors for Fatigue among SPBE Operators of PT Putra Arba Mandiri \\ Fellysca V. M. Politon*, Christine \\ Jurusan Sanitasi Poltekkes Kemenkes Palu \\ *(Fellyscavmpoliton@gmail.com)
}

\begin{abstract}
ABSTRAK
Kelelahan kerja merupakan stress yang banyak dirasakan oleh pekerja dalam bidang pelayanan terhadap manusia lainnya, seperti perawatan kesehatan, pendidikan, kepolisian, keagamaan. Suatu study mengenai kesehatan mental pekerja menemukan bahwa orang-orang yang mengalami perasaan tidak simpatik terhadap kliennya atau konsumen yang dilayaninya kepada rekan kerjanya dapat menciptakan suasana negatif diantara satuan kerja tersebut. Tujuan diketahuinya faktor risiko kelelahan kerja pada operator SPBE PT putra arba mandiri. Jenis penelitian cross-sectional. Populasi dalam penelitian ini adalah seluruh operator SPBE PT Arba Mandiri. Sampel diambil dengan random sampling atau pengambilan sampel secara acak dimana anggota populasi memiliki kesempatan yang sama untuk terpilih menjadi sampel yaitu 34 responden. Hasil penelitian menunjukkan bahwa secara umum kelelahan kerja tinggi sebanyak 1 responden (2,9\%). Kesimpulan kelelahan kerja banyak dialami pada umur $>40$ tahun sebesar $80 \%$, dengan tekanan darah rendah sebanyak $100 \%$ dan indeks massa tubuh yang kurang sebesar $50 \%$. Saran bagi perusahaan diharapkan untuk meningkatkan perhatian bagi kesehatan dan keselamatan para pekerja SPBE dengan berupaya agar pekerja dapat bebas dari alcohol dan bahan psikotropika berbahaya lainnya melalui pelaksanaan medical checkup secara rutin, dan para pekerja disarankan untuk berolahraga untuk menjaga stamina, cuti dan liburan diselenggarakan sebaik- baiknya.
\end{abstract}

Kata Kunci: kelelahan kerja; tekanan darah; indeks masa tubuh

\begin{abstract}
Work fatigue is a type of stress experienced by many people who work in other human service jobs, such as health care, education, police, religion, etc. The research of worker's mental health found that people who have unsympathetic feelings for their clients or consumers can create a negative atmosphere for co-workers among the workforce. The research purpose is to know the risk factors for fatigue in SPBE operator of PT Putra Arba Mandiri. This type of research uses a cross-sectional type. The population of the research was all SPBE operators of PT Arba Mandiri. Samples were taken by random sampling that members of the population had the same opportunity to be selected as a sample, specifically 34 respondents. The results of the research showed generally that the high work fatigue by 1 respondent (2.9\%). The conclusion that work fatigue is mostly perceived at the age of more than 40 years of $80 \%$, with low blood pressure as much as $100 \%$ and body mass index less than 50\%. Suggestions for companies are expected to increase attention to the health and safety of SPBE workers by making labor free of alcohol, drugs, and dangerous drugs through routine medical check-ups, and workers are advised to exercise to maintain stamina, leave and holidays are organized as well as it's good.
\end{abstract}

Keyword: fatigue; hypertension; body mass index

https://doi.org/10.33860/jik.v14i2.244

(C) 2020 by the authors. Submitted for possible open access publication under the terms and conditions of the Creative Commons Attribution (CC BY SA) license (https://creativecommons.org/licenses/by-sa/4.0/). 


\section{PENDAHULUAN}

Pemerintah sejak lama telah menerbitkan peraturan tentang keselamatan kerja dalam Undang-undang Nomor 1 Tahun 1970 guna mencegah terjadinya kecelakaan kerja. Tenaga kerja wajib mentaati semua petunjuk keselamatan kerja dan memakai alat-alat perlindungan diri bila memasuk tempat kerja. ${ }^{1}$ International Labour Organization (ILO) memperkirakan lebih dari 374 juta orang yang cedera atau luka atau jatuh sakit tiap tahun akibat kecelakaan terkait kerja dan menurut BPJS Ketenagakerjaan sebanyak 157.313 kasus kecelakaan kerja pada tahun 2018. ${ }^{2}$

Kelelahan kerja diartikan sebagai rasa lelah yang dirasakan oleh pekerja dengan gejala yang berbeda-beda pada setiap individu. ${ }^{3}$ Dalam sistem K3 Nasional dijelaskan untuk tidak hanya memperhatikan keselamatan kerja tetapi juga focus pada penyakit akibat kerja yang salah satunya kelelahaan kerja. Kelelahan kerja merupakan tekanan pikiran dalam pekerjaan yang dialami oleh pekerja sebagai Konsekuensi yang dialami dalam bekerja. kelelahan kerja adalah memburuknya hubungan pekerja dengan rekan kerja lainnya. Suatu study mengenai kesehatan mental pekerja menemukan bahwa orang-orang yang menghadapi keadaan tidak simpatik dari kliennya atau konsumen yang dilayaninya kepada rekan kerjanya dapat menciptakan suatu atmosfir negatif diantara satuan kerja tersebut. Pekerja yang mengalami kelelahan juga akan sering tidak masuk kerja dan mengambil waktu istirahat. ${ }^{4}$ Beberapa faktor lingkungan yang bisa menyebabkan kelelahan kerja seperti intensitas penerangan yang kurang, kebisingan dapat menjadi faktor yang menyebabkan kelelahan, selain itu juga faktor individu seperti usia pekerja dan masa kerja pekerja juga ikut mempengaruhi keadaan kelelahan yang dirasakan.

Hasil penelitian Latief (2017) pada pegawai PT. PLN (Pesero) Wilayah Sulawesi Selatan, Tenggara dan Barat menunjukkan terdapat hubungan yang signifikan antara sikap kerja dan kelelahan kerja. Selain sikap kerja, keadaan gizi atau status gizi merupakan salah satu penyebab kelelahan. ${ }^{5}$ Pada Pekerja dengan keadaan gizi yang baik akan memiliki kapasitas kerja dan daya tahan tubuh yang lebih baik. Pada keadaan gizi buruk, dengan beban kerja berat akan mengganggu kerja dan menurunkan efisiensi dan ketahanan tubuh sehingga mudah terjangkit penyakit sehingga mempercepat timbulnya kelelahan. Status gizi seseorang dapat diketahui melalui Tinggi badan dan berat badan dalam nilai IMT. ${ }^{6}$ Selain itu, tekanan darah juga berperan dalam terjadinya kelelahan kerja.

Untuk mencegah terjadinya kecelakaan kerja maka pekerja perlu sadar tentang pentingya keselamatan dan kesehatan kerja (K3). Perlu deteksi dini untuk mencegah kelelahan kerja yang dapat berujung pada kecelakaan kerja. Sehingga perlu dilakukan penelitian untuk mendeteksi parameter tersebut berupa Analisis faktor risiko kelelahaan kerja pada operator SPBE PT Putra Arba Mandiri di Palu.

\section{METODE}

Jenis penelitian cross sectional, pengambilan sampel dengan random sampling. Penelitian dilaksanakan di PT Putra Arba Mandiri Palu, Populasi 165 dan Sampel 34 operator, pengambilan data yang digunakan yaitu data primer dengan teknik wawancara karakteristik responden, pengukuran kelelahaan kerja dengan alat reaction timer, pengukuran tinggi \& berat badan, pengukuran tekanan darah yang dilaksanakan pada bulan September - November 2019, Analisis Univariat dilakukan untuk mengetahui frekuensi dan distribusi dari variabel yang diteliti dan analisis bivariat digunakan untuk menganalisis hubungan antara variabel bebas dan variabel terikat.

\section{HASIL}

Berdasarkan Tabel 1. Distribusi responden berdasarkan umur yang terbanyak yaitu pada kategori 18-30 tahun sebanyak 17 responden $(50,0 \%)$. Tekanan darah terbanyak yaitu pada kategori normal yaitu 26 reponden (76,5\%). Pada indeks masa tubuh yang terbanyak pada kelompok lebih yaitu 17 responden $(50,0 \%)$ dan karakteristik kelelahan kerja terbanyak yaitu pada kategori normal yaitu 21 responden $(61,8 \%)$.

Tabel 1. Distribusi Frekuensi Umur, Tekanan Darah dan Indeks Masa Tubuh

\begin{tabular}{lrc}
\hline Karakteristik & Jumlah & Persen (\%) \\
\hline Umur & & \\
$18-30$ th & 17 & 50,0 \\
$31-40$ th & 12 & 35,3 \\
$>40$ th & 5 & 14,7 \\
Tekanan Darah & & \\
$\quad$ Normal & 26 & 76,5 \\
Tinggi & 7 & 20,6 \\
Rendah & 1 & 2,9 \\
\hline
\end{tabular}




\begin{tabular}{lcc}
\hline Karakteristik & Jumlah & Persen (\%) \\
\hline IMT & & \\
$\quad$ Normal & 13 & 38,2 \\
Kurang & 4 & 11,8 \\
Lebih & 17 & 50,0 \\
Kelelahan Kerja & & \\
$\quad$ Normal & 21 & 61,8 \\
$\quad$ Sedang & 12 & 35,3 \\
Tinggi & 1 & 2,9
\end{tabular}

Data Primer, 2019

Berdasarkan Tabel 2. Menunjukan bahwa responden yang mengalami kelelahan kerja sedang terjadi pada usia $>40$ tahun sebanyak $80 \%$ dan pada usia 31-40 tahun mengalami kelelahan kerja tinggi sebesar 8,3\%. Operator yang mengalami kelelahan kerja sedang pada tekanan darah rendah sebanyak $100 \%$ dan pada kategori tinggi dengan tekanan darah tinggi yaitu 14,2\%. Operator yang mengalami kelelahan kerja dengan indeks massa tubuh (IMT) kurang mengalami kelelahan kerja sedang sebesar $50 \%$ dan sebesar $5,9 \%$ operator dengan IMT lebih mengalami kelelahan kerja tinggi.

Tabel 2. Distribusi Frekuensi Kelelahan Kerja Berdasarkan Umur pada Operator SPBE PT Putra Arba Mandiri Palu

\begin{tabular}{|c|c|c|c|c|c|c|}
\hline \multirow{3}{*}{ Variabel } & \multicolumn{6}{|c|}{ Kelelahan Kerja } \\
\hline & \multicolumn{2}{|c|}{ Normal } & \multicolumn{2}{|c|}{ Sedang } & \multicolumn{2}{|c|}{ Tinggi } \\
\hline & $\mathbf{n}$ & $\%$ & $\mathbf{n}$ & $\%$ & $\mathbf{n}$ & $\%$ \\
\hline \multicolumn{7}{|l|}{ Umur } \\
\hline 18-30 & 14 & 82,4 & 3 & 17,6 & 0 & 0,0 \\
\hline $31-40$ & 6 & 50,0 & 5 & 41,7 & 1 & 8,3 \\
\hline$>40$ & 1 & 20,0 & 4 & 80,0 & 0 & 0,0 \\
\hline \multicolumn{7}{|l|}{ Tekanan Darah } \\
\hline Normal & 18 & 69,2 & 8 & 30,8 & 0 & 0,0 \\
\hline Rendah & 0 & 0,0 & 1 & 100,0 & 0 & 0,0 \\
\hline Tinggi & 3 & 42,9 & 3 & 42,9 & 1 & 14,2 \\
\hline \multicolumn{7}{|c|}{ Indeks Masa Tubuh } \\
\hline Normal & 8 & 61,5 & 5 & 38,5 & 0 & 0,0 \\
\hline Kurang & 2 & 50,0 & 2 & 50,0 & 0 & 0,0 \\
\hline Lebih & 11 & 64,7 & 5 & 29,4 & 1 & 5,9 \\
\hline
\end{tabular}

\section{PEMBAHASAN}

Ketahanan fisik individu dipengaruhi oleh usia, dimana usia akan mempengaruhi tingkat kapasitas kerja dalam melakukan setiap pekerjaannya. Ketahanan otot manusia akan mengalami penurunan sebesar $15-25 \%$ pada kisaran 50-60 tahun, puncak kekuatan otot pada seorang laki-laki adalah 25-35 tahun, begitu pula dengan umur kisaran 45 tahun akan terjadi penurunan kekuatan otot dan semakin bertambahnya usia seseorang akan diikuti dengan penurunan kekuatan dalam bekerja baik secara fisik maupun psikis. ${ }^{7}$

Semakin bertambah umur menyebabkan jaringan otot mengkerut dan akan tergantikan oleh jaringan ikat, hal ini menyebabkan elastisitas otot berkurang dan mempengaruhi pada ketidakmampuan tubuh.

Berdasarkan hasil penelitian pada Operator SPBE PT Putra Arba Mandiri Palu dari 34 responden menunjukan bahwa yang mengalami kelelahan kerja sedang terjadi pada usia $>40$ tahun sebanyak $80 \%$ dan sebanyak $8,3 \%$ yang mengalami kelelahan kerja tinggi pada usia 3140 tahun, hal ini menunjukan bahwa usia $>40$ tahun lebih banyak mengalami kelelahan kerja sedang. Sehingga terdapat hubungan antara usia dengan kelelahan kerja, dimana semakin besar usia seseorang maka akan terjadi penurunan fisiologi dimana kekuatan otot mulai mengalami penurunan dengan demikian akan berpengaruh terhadap pekerjaan yang dilakukan sehingga mengalami perubahaan dalam kapasitas kerja yang dimiliki, dan mengakibatkan kelelahan kerja pada tenaga kerja.

Hasil penelitian ini sejalan dengan hasil penelitian yang dilakukan oleh Januar Atiqoh Dkk yang mengatakan bahwa ada hubungan antara usia dengan kelelahan kerja yang terjadi pada pekerja. Dimana pada kategori usia $>40$ tahun yang terbanyak didapatkan kelelahan kerja sedang. golongan usia tersebut masih tergolong dalam usia produktif, namun dalam hal kelelahan, baik fisik maupun kelelahan mental, dimana usia tersebut kapasitas kerja seseorang mulai berkurang hingga menjadi 
80\%-60\% dibandingkan dengan kapasitas kerja pada golongan umur 25 tahun. $^{8}$

Penelitian ini berbanding terbalik dengan hasil penelitian yang dilakukan oleh Tria melissa yang menunjukkan bahwa responden dengan tingkat kelelahan sedang berada pada kategori umur $>40$ tahun. Pada kategori umur 18-30 tahun terdapat responden yang merasakan kelelahan kerja tinggi sehingga tidak ada hubungan antara usia dengan kelelahan kerja seseorang. ${ }^{9}$ Berdasarkan hasil penelitian dari Sari Narulita Ningsih, pekerja yang mengalami kelelahan kerja terjadi pada usia 20 - 27 tahun. Pada hasil penelitian tidak ditemukan adanya hubungan antara usia dengan tingkat kelelahan kerja. ${ }^{10}$

Menurut Tarwaka intake oksigen akan menurun seiring bertambahnya usia, hal ini yang menyebabkan kebutuhan oksigen untuk menghasilkan energy berkurang sehingga dapat memicu kelelahan kerja. ${ }^{7}$

\section{Tekanan Darah}

hipotensi kondisi ketika tekanan darah berada dibawah 120/80mmHg, hipotensi pada dasarnya tidak membahayakan dan bisa dirasakan oleh siapa saja tetapi pada sebagian orang hipotensi ddapat menyebabkan pusing dan tubuh merasa lemas. ${ }^{11}$

Berdasarkan hasil penelitian pada Operator SPBE PT Putra Arba Mandiri Palu bahwa responden yang mengalami kelelahan kerja banyak didapatkan pada kategori tekanan darah rendah pada tingkat kelelahan sedang yaitu sebanyak $100 \%$. Menurut asumsi peneliti hal ini terjadi karena responden yang memiliki tekanan darah rendah hanya $2,9 \%$ sehingga belum bisa dikatakan bahwa tekanan darah merupakan faktor risiko terjadinya kelelahan kerja. Penelitian terdahulupun menyimpulkan tidak ada hubungan antara kejadian hipertensi dengan kelelahan kerja. ${ }^{12}$, namun ada penelitian lain yang menyimpulkan ada hubungan antara beban kerja dengan kejadian hipertensi. ${ }^{13}$

\section{Indeks Massa Tubuh}

Asupan makanan yang baik merupakan upaya dalam menjaga kesehatan yang baik, sehingga dapat mewujudkan pekerja sehat dan produktif. Asupan makanan yang tidak seimbang adalah salah satu penyebab kelelahan. Pekerja dengan asupan gizi yang baik akan memiliki kinerja dan daya tahan tubuh yang lebih baik, Bila asupan makanan tidak seimbang, serta tuntutan dalam pekerjaan yang tinggi dapat mengganggu produktivitas dalam bekerja serta menurunkan daya tahan tubuh menjadi lemah, dan rentan dengan penyakit sehingga dapat mempercepat timbulnya kelelahan. Keseimbangan gizi individu dapat diketahui dengan menghitung nilai IMT (Indeks Massa Tubuh). ${ }^{6}$

Supariasa mengatakan bahwa masalah gizi seperti kekurangan dan kelebihan pada orang dewasa (usia 18 tahun ke atas) merupakan masalah penting yang harus diperhatikan. Hal ini dikarenakan selain mempunyai risiko terhadap penyakit tertentu juga menyebabkan pekerja cepat mengalami kelelahan dan dapat mempengaruhi produktivitas. ${ }^{14}$

Berdasarkan hasil penelitian pada Operator SPBE PT Putra Arba Mandiri Palu bahwa responden yang mengalami kelelahan kerja banyak didapatkan pada pekerja kategori sedang dengan IMT kurang yaitu sebanyak 50\% dan yang terendah pada kategori tinggi dengan IMT lebih sebanyak 5,9\%. Hasil penelitian ini menunjukan bahwa IMT merupakan salah satu faktor dalam menentukan kelelahan kerja. Sama halnya dengan pendapat yang dikemukakan oleh Suma'mur yaitu seseorang dengan status gizi kurang cenderung mengubah cadangan gizi untuk menjadi energi saat beraktivitas. Masalah perbaikan dan peningkatan gizi merupakan hal yang sangat penting dalam usaha menyehatkan dan meningkatkan produktivitas kerja..$^{15}$

Hasil penelitian ini berbeda dengan hasil penelitian yang dilakukan oleh Sari Narulita Ningsih, sebagian besar pekerja dengan IMT normal mengalami kelelahan kerja. Sehingga IMT tidak mempengaruhi tingkat kelelahan kerja seseorang. ${ }^{10}$ Begitupun dengan penelitian yang dilakukan oleh Ramayanti yang menunjukkan bahwa tidak ada hubungan antara status gizi dengan kelelahan kerja, ${ }^{16}$ dan hasil penelitian yang dilakukan oleh Verawati mengenai hubungan tingkat kelelahan subjektif dengan produktivitas pada tenaga kerja menunjukkan tidak ada hubungan antara status gizi dengan kelelahan kerja. ${ }^{17}$

\section{SIMPULAN DAN SARAN}

Berdasarkan penelitian yang telah dilakukan di SPBE PT Putra Arba Mandiri Palu, ditemukan kelelahan kerja pada umur $>40$ tahun sebesar $80 \%$, dengan tekanan darah rendah sebanyak $100 \%$ dan indeks massa tubuh yang kurang sebesar $50 \%$. Bagi perusahaan diharapkan untuk meningkatkan perhatian bagi kesehatan dan keselamatan para pekerja SPBE 
dengan mengupayakan tenaga kerja bebas alkohol, dan zat adiktif berbahaya lainnya melalui pelaksanaan medical checkup secara rutin, untuk para pekerja disarankan untuk berolahraga untuk menjaga stamina tubuh, cuti dan liburan digunakan dengan sebaik- baiknya.

\section{DAFTAR PUSTAKA}

1. Republik Indonesia. Undang-undang Nomor 1 Tahun 1970 tentang Keselamatan Kerja. Jakarta: Sekretariat Negara RI; 1970.

2. Local Initiative for Osh Network. 157.313 Kasus Kecelakaan Kerja Di 2018 [Internet]. http://lionindonesia.org/. 2019. hal. 1. Tersedia pada: http://lionindonesia.org/blog/2019/04/20/157 -313-kasus-kecelakaan-kerja-di-2018-iloingin-peningkatan-kondisi-kerja/

3. Irwanto BSP. Analysis of Mental and Physical Fatigue Risk Factors in Utility Unit of Petrochemical Company. Indones J Occup Saf Heal [Internet]. 30 April 2020;9(1):21. Tersedia pada: https://ejournal.unair.ac.id/IJOSH/article/view/12120

4. Eraliesa F. Hubungan Faktor Individu dengan Kelelahan Kerja pada Tenaga Kerja Bongkar Muat di Pelabuhan Tapaktuan Kecamatan Tapaktuan Kabupaten Aceh Selatan Tahun 2008 [Internet]. Universitas Sumatera Utara; 2009. Tersedia pada: http://repository.usu.ac.id/handle/123456789 $/ 14721$

5. Latief AWL. Analisis Faktor yang Berhubungan dengan Kelelahan Kerja Pegawai PT PLN (Persero) Wilayah Sulawesi Selatan, Tenggara, dan Barat: an Analysis on Factors Correlated to Officials Work Fatigue of PT PLN (Persero) of South, Southeast, and West Sulawesi Region [Internet]. Universitas Hasanuddin; 2017. Tersedia http://103.195.142.59/opac/detailopac?id=35860

6. Windyananti A. Hubungan antara Kelelahan Kerja dengan Stress Kerja pada Tenaga Kerja di Pengolahan Kayu Lapis Wreksa Rahayu, Boyolali [Internet]. Universitas Sebelas Maret; 2010. Tersedia pada: https://digilib.uns.ac.id/dokumen/detail/1555 0/Hubungan-antara-kelelahan-kerja-denganstress-kerja-pada-tenaga-kerja-dipengolahan-kayu-lapis-Wreksa-RahayuBoyolali

7. Tarwaka. Ergonomi Industri: Dasar-Dasar Ergonomi dan Aplikasi di Tempat Kerja. II.
Jakarta: Harapan Press; 2019.

8. Atiqoh J, Wahyuni I, Lestantyo D. FaktorFaktor Yang Berhubungan Dengan Kelelahan Kerja Pada Pekerja Konveksi Bagian Penjahitan Di Cv. Aneka Garment Gunungpati Semarang. J Kesehat Masy Univ Diponegoro [Internet]. 2014;2(2):119-26. Tersedia pada: https://ejournal3.undip.ac.id/index.php/jkm/a rticle/view/6386

9. Melissa T, Dwiyanti E. Gambaran Kelelahan Kerja Subjektif pada Operator Mesin Produksi Pakan Ikan. Indones J Occup Saf Heal [Internet]. 2018;7(2):191-9. Tersedia pada: https://ejournal.unair.ac.id/IJOSH/article/view/4925/ pdf

10. Ningsih SNP, Nilamsari N. Faktor yang Berhubungan dengan Kelelahan pada Pekerja Dipo Lokomotif PT Kereta Api Indonesia. J Ind Hyg Occup Heal [Internet]. 2018;3(1):69-82. Tersedia pada: doi.org/10.21111/jihoh.v3i1.2439

11. Willy T. Hipotensi [Internet]. alodokter.com. 2019. Tersedia pada: https://www.alodokter.com/hipotensi

12. Lestari N. Hubungan Kelelahan Kerja dengan Kejadian Hipertensi pada Lansia di DusunJambon Trihanggo Gamping Sleman [Internet]. Universitas 'Aisyiyah Yogyakarta; 2019. Tersedia pada: http://digilib2.unisayogya.ac.id/xmlui/handle /123456789/104

13. Sunarsih S, Ilyas H. Hubungan Beban Kerja Dengan Terjadinya Penyakit Hipertensi Di Poliklinik Universitas Lampung. J Ilm Keperawatan Sai Betik. 2018;13(1):42-7.

14. Supariasa IDN. Penilaian Status Gizi. Jakarta: EGC; 2013.

15. Suma'mur P.K. Higiene Perusahaan dan Kesehatan Kerja (HIPERKES). Jakarta: Sagung Seto; 2013.

16. Ramayanti R. Analisis Hubungan Status Gizi dan Iklim Kerja dengan Kelelahan Kerja di Catering Hikmah Food Surabaya. Indones J Occup Saf Heal [Internet]. 16 Maret 2017;4(2):177. Tersedia pada: https://ejournal.unair.ac.id/IJOSH/article/view/1748

17. Verawati L. Hubungan Tingkat Kelelahan Subjektif dengan Produktivitas pada Tenaga Kerja Bagian Pengemasan di CV Sumber Barokah. Indones J Occup Saf Heal [Internet]. 16 Maret 2017;5(1):51-60. Tersedia pada: https://ejournal.unair.ac.id/IJOSH/article/view/3799 